Research

\title{
The Namibian bioeconomy: transformation to a sustainable society?
}

\author{
Anne Heeren-Hauser ${ }^{1} \cdot$ Ahmad Cheikhyoussef $^{2} \cdot$ Percy M. Chimwamurombe ${ }^{3}$
}

Received: 16 October 2020 / Accepted: 13 November 2020

(c) The Author(s) 2020 OPEN

\begin{abstract}
Worldwide, bioeconomy is promoted as an 'engine for sustainable development'. However, increasingly, the notion that 'the bioeconomy' will facilitate sustainable development per se is challenged. Based on the assumption that when leaving the relations between 'nature' and 'society' unquestioned, inherent inequalities are rather reproduced than overcome, we draw upon a social-ecological framework to analyse the societal relations to nature in the Namibian bioeconomy. In Namibia, with independence, an array of different benefit-sharing mechanisms have been developed to implement local participatory governance structure, which will be further streamlined under the newly introduced access and benefit-sharing law. Results show that despite efforts to facilitate a diversity-based bioeconomy, separating structures and trade-offs are persistent. Images of 'nature', like the 'eternal Namibian landscape', that draw upon colonial notions are frequently used to market indigenous natural products. Institutions to 'nature' that guarantee fair and equitable terms of trade are often only short-term and/or small-scale, e.g. as shown at the case of Devil's claw, Hoodia and Namibian Myrrh. Even when perspectives cannot be assigned in a stereotypical way between user and provider, and instead, all actors refer to biodiversity and traditional knowledge as 'welfare of the people','cultural heritage,' input for R\&D','community benefit', and 'marketing tool', a rational-instrumental reasoning tends to be favoured of a normative-ethical one. A more diversified awareness towards the dialectics entailed in the conception, making, and management of 'nature' potentially inhibiting an inclusive sustainable development is relevant at any theory-practice interface, including development project-management and environmental policy-making.
\end{abstract}

Keywords Bioeconomy - Societal relations to nature - Access and benefit-sharing · Indigenous knowledge systems . Indigenous natural products · Namibia

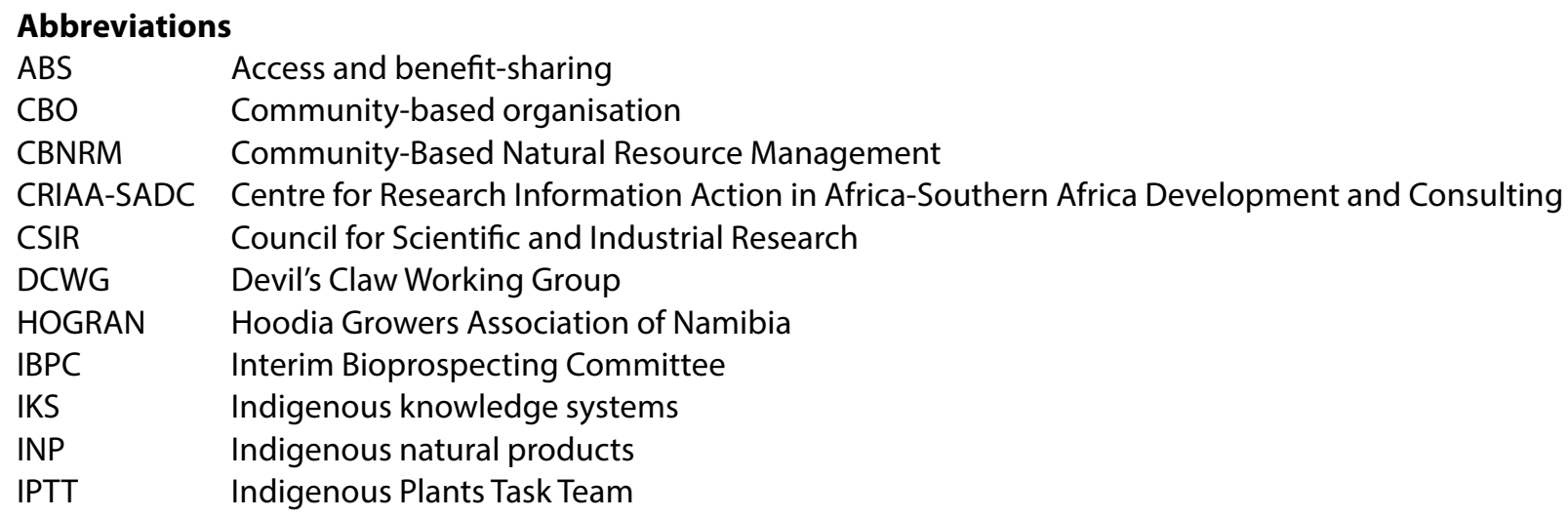

Anne Heeren-Hauser, Anne-Heeren@web.de | ${ }^{1}$ Faculty of Architecture and Landscape Sciences, Leibniz University Hannover (LUH), Hannover, Germany. ${ }^{2}$ Science and Technology Division, Multidisciplinary Research Centre, University of Namibia (UNAM), Windhoek, Namibia. ${ }^{3}$ Department of Natural and Applied Sciences, Namibia University of Science and Technology (NUST), Windhoek, Namibia.

Discover Sustainability $\quad$ (2020) 1:8 $\quad$ https://doi.org/10.1007/s43621-020-00007-6 


$\begin{array}{ll}\text { IRDNC } & \text { Integrated Rural Development and Nature Conservation } \\ \text { KCINPT } & \text { Kunene Conservancies Indigenous Natural Products Trust } \\ \text { MEFT } & \text { Ministry of Environment, Forestry and Tourism } \\ \text { NBRI } & \text { National Botanical Research Institute } \\ \text { NCRST } & \text { National Commission on Research Science and Technology } \\ \text { NGO } & \text { Non-governmental organisation } \\ \text { SADF } & \text { South African Defence Force } \\ \text { SRN } & \text { Societal relations to nature } \\ \text { UNAM } & \text { University of Namibia } \\ \text { UNEP } & \text { United Nations Environment Programme }\end{array}$

\section{Introduction}

Since the beginning of the twenty-first century, bioeconomy ${ }^{1}$ has been promoted as the 'world's new economic engine' for sustainable development that addresses the challenges of humanity: overexploitation of natural resources, climate change, economic crisis, and poverty [3, 4]. In order to facilitate the achievement of the Sustainable Development Goals, the United Nation proclaimed: a sustainable bioeconomy can feed the world and save the planet [5]. Thereby, the vision is created that bio-based technological innovations, especially in the energy and biotechnology sector, will spur a wave of technological disruptions that is benefiting businesses, society, and nature alike [6]. Estimates suggest that the transformative potential is of large-scale: currently, the bioeconomy accounts for $13 \%$ of world's trade, corresponding to a value of about 2 trillion US\$ [7] (p. 221).

However, the unexplored question is: How to create an inclusive sustainable bioeconomy based upon the principle of fairness and equity? Especially, the 'how to do sustainability right' is highly debated: While some scholar argue for a technology-driven approach to facilitate the integration of sustainability into the bio-based industries [8], other criticise the bioeconomy for its technological fix, pre-empting alternative visions [9]. Empirical studies, especially in Europe, tend to focus on eco-environmental aspects of how to transfer from an extractive fossil-fuel to a bio-based, green, and circular re-use economy $[2,10-13$,$] , thereby, paying limited attention to agro-societal aspects.$

A call has been made for a diversity-based approach, e.g. as expressed at the Global Bioeconomy Summit, 2015 that there is not one single bioeconomy but many 'bioeconomies' [14]. However, the proclamation of an integrated approach has the potential to fall behind its own aspirations. Consequently, we question overly optimistic stances on the 'transformative potential' of the bioeconomy, e.g. the declaration of the German Bioeconomy Council to create bio-based value networks of mutual beneficiation to ensure a "Sustainable Bioeconomy For All" [15] (p. 13). Therefore, we argue that when leaving inherent contradictions unquestioned, these may be reproduced rather than overcome. For example, when stating that there are "opportunities for strategic partnership between Africa and Europe, Africa being rich in biomass resources with a growing science capacity, Europe being rich in science capacities but with limited biomass resource base" [16], this implies a stereotypic North-South relation based on the structural separation 'developed/industrialised'.

Beyond anti-commercial attitudes disqualifying the bioeconomy "as the wrong way" in general [19], there is a need for a transdisciplinary approach that does not treat natural and social aspects as mere supplements, but as constituting factors that mutually depend upon each other. The main objective of this paper is the analysis of the societal relations to nature (SRN) in the Namibian bioeconomy. The underlying assumption is that inherent inequalities in the bioeconomy can only be overcome when taking into account the inherent contradictions characterizing the relations between the 'natural' and the 'social'.

A differentiated understanding of the dialectics entailed in the conception, making, and management of 'nature', may also be relevant for the general debate on 'sustainable development'. Drawing upon a social-ecological framework,

\footnotetext{
1 There are a multitude of understandings, definitions, and practices that draw upon different aspects of the bioeconomy [1]. Firstly, the bioeconomy is recognised as a (new) theoretical concept to integrate environmental, social and economic impact assessment. Secondly, the bioeconomy refers to a (new) strategic-political tool (re-)defining regional and national development agendas. Thirdly, the bioeconomy represents a (new) vast developing business sector by itself [2]. All three aspects need to be kept in mind in the analysis of the bioeconomy.

2 The presentation of Western 'developed countries' as 'bioeconomy leader' [17] and the 'developing world' across Africa, Asia, and Latin America as mere 'adapter' is increasingly being challenged, and instead, the image of an "equitable business partnership" is created, e.g. as part of the Biolnnovation Africa program under the German Marshall Plan with Africa [18].

3 'Nature' in single quotation marks must not merely be understood as naturally given, but also as socially constructed [20].
} 
we conceptualise 'sustainability' as a discursive practice that continuously is being (re-)negotiated by the diverse actors involved. Thereby, any notion on 'sustainability' always already incorporates, often unexpressed, presumptions about 'fairness' and 'equity'. Thus, a social-ecological perspective does not only represent a useful tool for transdisciplinary sustainability research, in principle, it may also be relevant whenever a theory becomes translated into a practical context, e.g. development project-management and environmental policy-making.

In this paper, we take the Namibian bioeconomy as a case study. In Namibia, a unique fauna and flora has been formed under semi-arid desert and savannah conditions and the variety of indigenous plants, animals, fungi, micro-organisms, and marine organisms makes the commercial utilisation of such resources, frequently referred to as bioprospecting, ${ }^{4}$ very attractive. Since the mid-1990s, the principle of benefit-sharing has been integrated into environmental policymaking. Today, several indigenous natural products (INP) have been commercialised based upon a pro-poor development strategy. INP-trade accounts for $4.5 \%$ of the gross domestic product and is projected to increase [22]. In future, the commercial utilisation of indigenous knowledge systems (IKS) will be regulated under the newly introduced Namibian access and benefit-sharing (ABS) law.

In the analysis of the SRN in the Namibian bioeconomy our guiding questions are: Which SRN are prevailing? What inherent contradictions exist? Are certain perspectives favoured over others? In the following, firstly, we will highlight some methodological considerations. We will introduce the social-ecological framework and describe how it has been adapted to suit the analysis in the Namibian bioeconomy. Then, the results will be presented: A short overview on the history of the Namibian bioeconomy is given followed by a presentation of current images of 'nature' in the marketing of INPs. Namibian INP-trade is further studied by highlighting (changing) institutions of 'nature' at the example of ABS/ biotrade cases, namely Devil's claw, Hoodia and Namibian myrrh. This is followed by a presentation of understandings of 'nature' and respective practices with 'nature' of actors. Finally, the 'transformative potential' of the Namibian bioeconomy for sustainable development will be discussed by focusing on the dialectics entailed in the conception, making, and management of 'nature'. Thereby, specific attention will be drawn on possible implications in the theory-practice interface.

\section{Methodological considerations}

Several approaches exist that engage in constructive criticism on the Sustainable Development Goals [23], one of which is social ecology. In this perspective, 'sustainability' is conceptualised as a discursive practice, continuously questioned and challenged by diverse actors. Thereby, we follow Becker and Jahn [24], who describe the guiding principle 'sustainable development' as a "blueprint for discussion over desired societal developments" (p. 57). While the main advantage of this concept lies in its broad acceptance securing a broad international consensus across science, practice, and politics, its major limitation refers to its vagueness, opening up a space for a variety of different interpretations. In this perspective, the sustainable development-debate represents a controversially structured discursive field that summons a diverse range of concepts of nature, or "cosmologies" that are linked to a range of a priori of what 'fairness' and 'equity' means and how it is best to be achieved [25].

In social ecology, the 'social-ecological crisis' is taken as a starting point. The main idea is that environmental impacts are often the combined result of complex interactions of both natural and societal aspects, and thus, it is impossible to designate them as one singular modality. Further, the 'social-ecological crisis' can only be understood in terms of their historical emergence: natural and societal structures and processes represent a "historical index" that "keeps awake memories of the past, which (...) are still present in its effects" [26] (p. 16). Likewise, when singularly applying naturalscientific or sociological approaches, either socio-cultural or biophysical aspects tend to be neglected, and thus, the full dimension of the 'social-ecological crisis' cannot be captured. In the attempt to overcome this 'double blindness', socialecological research represents a mediating approach that integrates diverse epistemic understandings [24].

SRN can be defined as the "relations between nature and society in their historical development" [27] (p. 5). They are grounded in basic structure of desire, e.g. basic needs, and become apparent as culturally specific and historically variable forms and practices in our everyday-life, so called patterns of regulation. When analysing such pattern of regulation entailed dichotomous structures become apparent, e.g. realism/constructivism, nature/culture, and

\footnotetext{
${ }^{4}$ Bioprospecting, defined as the "exploration of biodiversity for commercially valuable genetic and biochemical resources" [21] (p. 3), is often contrasted from biotrade, which refers to the actual marketing of bio-based resources, ingredients and final products. However, both activities are closely related as will be further discussed in the course of this paper.
} 
subject/object, upon which a dialectic critique can be applied that questions binary oppositions as "powerful social constructs" [27] (p. 5). The visualisation of 'nature' as a societal category does not only reflect upon the interconnectivity between natural and social aspects, furthermore, functional idealisations made 'in the name of nature' come into perspective. Such idealisations always incorporate elements of hierarchies and power relations. Henceforth, endeavours for 'sustainability', e.g. as perused under the Sustainable Development Goals, can be understood as a "domination of nature" [28]. Nevertheless, such demarcation and respective domination must not be understood as fixed or permanent: as they are embedded into historical process, they constantly change and evolve with regard to their material, symbolic, and normative ascriptions [29].

Figure 1 shows the conceptual framework applied in this study: Against the background of the 'social-ecological crisis' and 'sustainability visions', SRN are conceptualised as an overlapping interface between 'nature' and 'society'. SRN represent generalised societal references to 'nature', and thus, always already incorporate a reflective moment. Thus, analytically, the mutually interdependent interactions between actors and biodiversities can only be captured in the form of every-day notions, in this case images, understandings, institutions and practices of/with 'nature' [20].

The main assumption providing the basis for the subsequent discussion is that inherent inequalities in the bioeconomy can only be overcome when looking at the inherent contradictions within the SRN. Further, we propose that SRN may serve as functional idealisations. For example, a presentation of biodiversity as 'competitive advantage' rests upon a linear model of industrial modernisation. This implies that biotechnological innovations, once initiated, will spur sustainable development mainly in terms of efficiency gains, and thus, the complex interrelations between

Fig. 1 Conceptual framework: the societal relations to nature in the Namibian bioeconomy (Source: adapted from [27, p. 10])
Fig. 2 a Devil's claw (Harpagophytum sp.), b Hoodia (Hoodia gordonii) and c Namibian myrrh (Commiphora wildii) (Source a, b NBRl; c IRDNC)
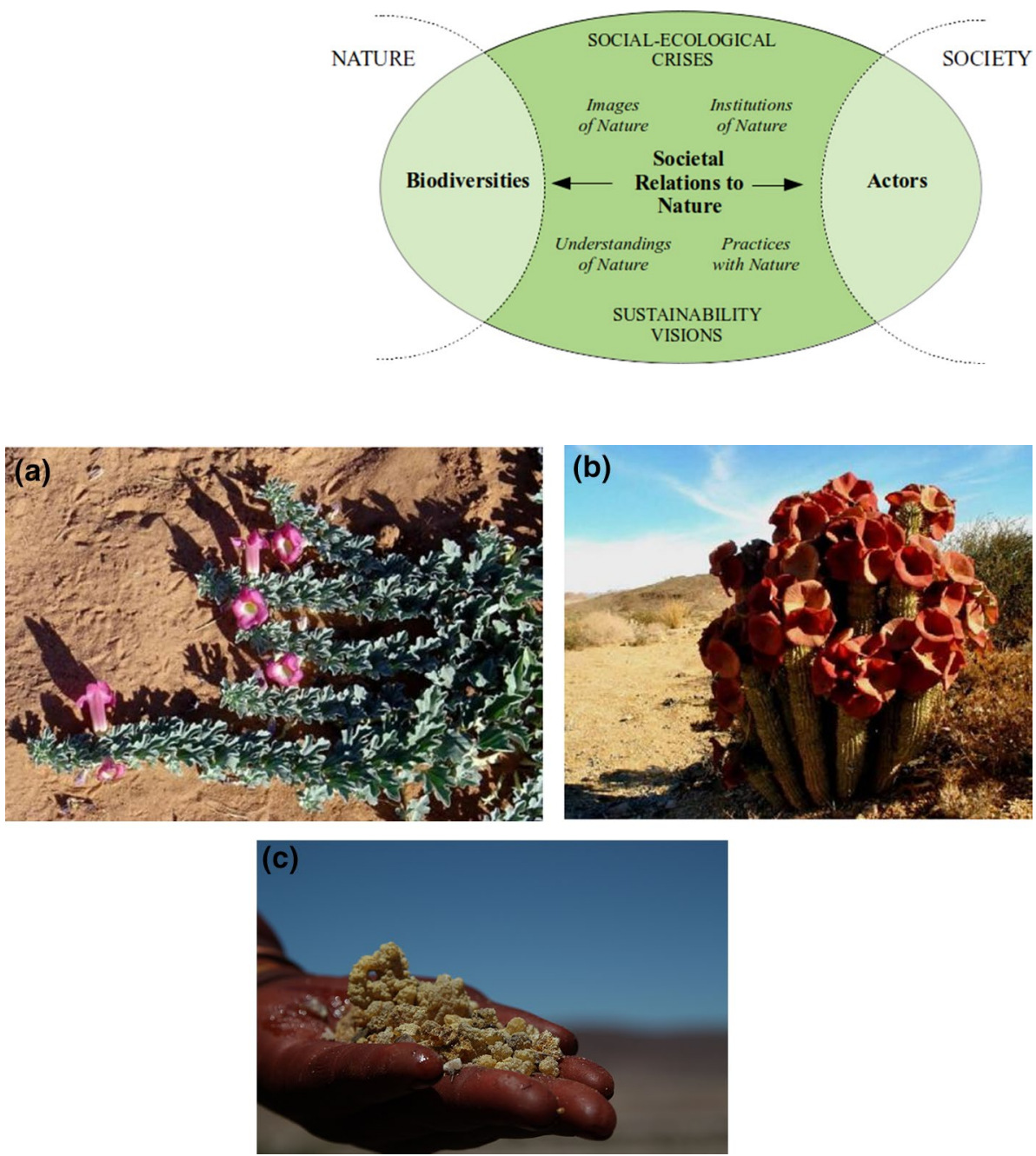
natural, social, cultural, economic, and political aspects are subjugated under an economic rationale. ${ }^{5}$ When analysing the Namibian INP-trade we focus on three case studies, namely Devil's claw, Hoodia and Namibian myrrh (Fig. 2).

The data used as a basis has been derived in the context of an ongoing PhD study. A two-fold method has been applied, including document analysis and narrative interviews. The document analysis refers to the assessment of environmental laws and regulations, workshop reports, research publications, websites as well as newspaper articles [30]. Furthermore, key stakeholders in the Namibian bioeconomy were interviewed, including governmental and community representatives, commercial actors, researchers as well as non-governmental organisations (NGOs). A total of 32 interviews were conducted in a one-to-one set-up between 2015 and 2017. Thereby, an open-end interview format was chosen: instead of falsifying a pre-defined hypothesis, the 'inner logic' of everyday theoretical conceptions was captured [31]. A reconstructive analysis using $f 4$ analysis was conducted to determine SRN as subjective descriptions [32], by asking: What constitutes 'biodiversity' and 'traditional knowledge' in terms of their material naturalness as well as societal fabrication. Besides analytical categories (marked in single quotation), also so called in-vivo codes are used that emphasise the actual spoken word (marked in double quotation). Prior to publication, follow-up interviews were carried out to allow for feedback on preliminary interpretations. Comments are included in the discussion to bridge between scientific and non-scientific notions.

\section{Results-The societal relation to nature in the Namibian bioeconomy}

\subsection{Images of 'Nature' in the Namibian bioeconomy}

A detailed overview of the history of the Namibian bioeconomy goes well beyond the scope of this paper, however, current SRN can only be understood by embedding them in its historical context. Namibian historic records mainly focus on the period of colonial occupation. In the late nineteenth century, the German Reich instituted 'rights' over land, resulting in violent conflicts with the native population. The ongoing resistance was responded to with the genocide of the Herero and Nama people. In 1915, South Africa occupied the Namibian territory, which was replaced by a Trusteeship agreement under the United Nations after World War II. Under the South-African occupation, the apartheid regime was enforced that was characterised by separate development under white supremacy. The route to independence was pushed both by internal and external pressure. In the 1960s, the South West Africa People's Organisation's (SWAPO) was founded as a nationalist movement in support of the Namibian people. In 1972 the United Nations declared South Africa's presence as illegal and recognised SWAPO as the sole legitimate representative of Namibia. However, under tense negotiation, it took until 1998 that first democratic elections were held under United Nation supervision. Eventually, on the 9th of February 1990 the Namibian constitution became adopted [33-35].

Telling the Namibian story as a long-standing period of colonisation-which after an enduring struggle for liberation resulted in independence-risks losing out of sight the pre-colonial history, which dates back to 400 AD [36]. Friedman [37] (p. 32) describes pre-colonial Namibia as a'mediating space' between migrating Oshiwambo, Otjiherero, and Khoikhoi-speaking people, among other groups. Communal organisational structures were diverse: While Khoi/San people practised a nomadic lifestyle as hunter-gatherers, Otjiherero people lived as decentralised pastoralists, and Oshiwambo people were organised in kingship. Knowledge structures and rights to land and resources are diverse, and moreover, subject to continuous (re-)negotiation (some till today) [38].

Especially in the Namibian Tourism Industry, the image of the vast, untouched, 'empty space' is frequently used in advertisement to emphasise the country's 'distinctiveness'. In the Namibian bioeconomy this image is frequently employed as well. For example, the German-based online portal NamShop presents Namibian natural products as: "Namibia-The African Kaleidoscope: Unique landscapes, embedded between two deserts, endless vastness scattered to the four winds and a fascinating wildlife, which you rarely find in Africa" (https://www.namshop.de). When predominantly employing a static image of the 'eternal Namibian landscape', also associated cultures may appear as fixed in time, and thus, unchangeable. Even when a description of Namibia as "land of contrasts" [ibid.] potentially allows integrating multiple perspectives, the nature/culture-divide is rather reinforced than overcome. Likewise, even when acknowledging the

\footnotetext{
${ }^{5}$ Please note that as a Grounded Theory informed research design we do not start with a theory-derived hypothesis, but with a set of research questions subject to continuous re-formulation in the course of the study to fit field relevance. Thus, the results can be understood as empirically-derived hypotheses of the mediation between 'nature' and 'society' grounded in real data.
} 
growing "consciousness for ethnic creativity" [ibid.] there is the danger while prioritising natural-material aspects to treat cultural-ethnic issues as secondary matters. Another notion with a similar concern arises when emphasising 'purity', e.g. as advertised on the website Namibian Naturals:"(...) valuable and pure natural products with selected ingredients which unite the extraordinary and exceptional of this countries' special nature" (https://www.namibian-naturals.de). Presenting Namibian indigenous plants and products as 'naturally given' that merely have to be 'discovered' draws upon images of colonial bioprospecting. For example, under the brand Desert Secrets products are advertised as "Timeless, with an ancient wisdom that has taken aeons to form under the vast blue and starlit sky, they hold a magic that you find only in the rare and special places of the Earth" (https://www.desert-secrets.com).

Even when the Namibian bioeconomy is still mainly characterised by images of 'nature' that draw upon colonial notions, increasingly diversity-informed notions are used as well to advertise Namibian natural products.

\subsection{Institutions of nature' regulating the Namibian bioeconomy}

Namibia inherited a society that is characterised by inequalities and massive social fragmentation, caused by German colonial appropriation and racial segregation under South African apartheid rule. Therefore, since independence the vision of a unified nation has been promoted under the slogan 'One Namibia, one Nation', or in its newer version 'Unity in Diversity' [39]. However, inequalities remain persistent. Chinsembu et al. [40] state that, historically, Namibia benefited little from the commercialisation of its indigenous natural resources and this "prism of economic dispossession" (p. 6788) needs to be overcome. Drawing upon dependency theory, a call has been made for an alternative development paradigm beyond modernist approaches, frequently referred to as "African Renaissance" [41-43]. ${ }^{6}$

In the early 1990s, bioprospecting endeavours were celebrated as a 'Green Eldorado', or 'Green Rush' to spur development objectives [45]. As a result, the convention on biological diversity was adopted, and since then, worldwide, attempts have been made to regulate the commercial use of indigenous resources under so called ABS measures.

In general, there are different approaches towards ABS: On the one hand ABS is conceptualised as a tool for 'historical reparation': with the onset of colonialisation, bioprospectors' have collected plant materials and established ex-situ collections, e.g. botanical gardens. Even today, information on potentially interesting plant traits is often freely available, e.g. in scientific publications and databases. The misappropriation of plant materials and associated traditional knowledges has frequently been criticised as biopiracy. The main argument is that "local and indigenous communities have acted historically as keepers, or even developers of biological diversity, and thus, should be 'compensated' by those who benefit from their care and labour" [46] (p. 1487). On the other hand ABS is conceptualised as a 'market for biodiversity' where user and provider negotiate over the conditions of exchange. ABS-agreements are reached where access to biodiversity is granted in exchange to specific compensation measures, including monetary benefits, e.g. license and royalty payments, and non-monetary benefits, e.g. technology transfer and capacity building [47]. ${ }^{7}$

While, theoretically, there is a strong justification for $A B S$, the idea that by creating a market for biodiversity sufficient means are generated to finance nature conservation and support rural livelihoods mainly fails in reality: there are rather ambiguous results with regard to the provision of ABS for benefit-sharing [50, 51]. However, as Shikongo [52] has shown at the Namibian case, the potential for institutional learning is facilitated under a polycentric approach that integrates beside governmental actors further private as well as civil society stakeholders, e.g. NGOs and community-based organisations (CBO).

In Namibia, with independence, the process of developing a national ABS-approach has been initiated in the late 1990s. The Namibian constitution - at times referred to as one of the most forward-looking ones in the world

\footnotetext{
${ }^{6}$ Recently, Namibia has been re-classified as an 'upper middle-income country' [44]. However, this 'development' is seen as highly controversial as the relatively high-income status masks high levels of inequality. Poverty incidence rates are about $30 \%$, with a high share of this population living below the severe poverty line of 2 US\$ per day.

7 Despite strong ethical reasoning, ABS has mainly been conceptualised from an economic perspective. According to Richerzhagen [48] the main principles of ABS are (1) the sovereign right of states over their genetic resources, (2) the internalisation of positive externalities of biodiversity conservation, and (3) the bilateral contract between user and provider. By declaring the sovereign right of states over biodiversity property rights are assigned to intangible plant part, i.e. genetic information and traditional knowledge. As a result, access to information upon plants is turned from a public into a private good, which is associated with increased levels of excludability and rivalry. These rights can be further assigned to local and indigenous communities. By integrating the positive externalities of biodiversity conservation the value of local conservation measures-usually remaining uncompensated-becomes quantified in terms of their contribution towards securing the global level of biodiversity [49]. However, an integrated assessment of underlying assumptions from a social-ecological perspective is still outstanding.
} 
[53] - mandates under Article 95/1 for the "maintenance of ecosystems, essential ecological processes and biological diversity of Namibia and utilisation of living natural resources on a sustainable basis for the benefit of the Namibians, both present and future" [54]. In 1994, Namibia's 1st National Biodiversity Strategy and Action Plan was launched, guiding a range of national policies, laws, and regulations on how to govern access to indigenous resources, which was updated in $2014[55,56]$. A critical element is the facilitation of integrative, self-determined, and participatory local governance structures, e.g. as furthered under the Community-Based Natural Resource Management (CBNRM) program [57, 58]. More specifically, in 2000 Namibia's Indigenous Plants Task Team (IPTT) was formed, a multi-stakeholder group promoting the emerging biotrade industry. Under the Ministry of Environment, Forestry and Tourism (MEFT), the Interim Bioprospecting Committee (IBPC) was set-up to coordinate ABS-related issues [59]. Thereby, IKS are seen as an essential part of developing the Namibian system of innovation [60]. In 2015 the National Programme on Research, Science and Technology and Innovation was set-up to promote "indigenous home-grown technologies" [61]. Further, a national IKS-database is created under the custodianship of the National Commission on Research Science and Technology (NCRST). Existing structures will be streamlined under the newly introduced Access to Biological and Genetic Resources and Associated Traditional Knowledge Act 2, 2017 (thereafter Namibian ABS law). The major objective is to "regulate access to biological or genetic resources and associated traditional knowledge, (...) innovation, practices and technologies (...) to protect the rights of the local communities to provide a fair and equitable mechanism for benefit sharing" [62] (p. 2). Currently, a detailed ABS regulation is being developed to implement, enforce, and monitor such structures.

In Namibia, the commercialization of INPs has been taken up as a national approach based on multi-stakeholder involvement. Several INPs have been commercialised that are subject to a range of benefit-sharing arrangements.

In 2012, a market study for Namibian INPs was conducted as part of the Capacity Building for Biotrade Project under the United Nations Environment Programme (UNEP). Thereby, a pro-poor growth strategy has been suggested: "The move towards a green economy seeks to develop and capitalise on those resources available to the poorest segments of the population, incorporating marginalised communities into the market economy and ensuring that they receive a fair share of the benefits derived from the productive activities in which they engage" [22] (p. 4). That time it was estimated that trade in Namibian INPs is contributing $4.5 \%$ towards the gross domestic product. Unfortunately, no more recent market data is available. As shown in Table 1, the annual volumes and values are highly fluctuating, in 2008 about 713.000 tons were traded at a value of 24 million N\$, while in 2012 about 557.000 tons were traded at a value of about 26.7 million $\mathrm{N} \$$. Thereby, an average increase in price/kg raising from about $34 \mathrm{~N} \$$ to $53 \mathrm{~N} \$$ was achieved.

The above presented overview indicates that commodities traded as raw materials, e.g. devil's claw, tend to correspond with lower values, when compared to semi-processed products, such as Marula, Ximenia, and Kalahari melon oils.

Table 1 Namibian indigenous natural products. Source: adapted from $[63,64]$

\begin{tabular}{|c|c|c|c|c|}
\hline Product & Year & Volume (kg) & Value (N\$) & $\mathrm{N} \$ / \mathrm{kg}$ \\
\hline Devil's claw ${ }^{a}$ & 2008 & 686.000 & 21.000 .000 & 31 \\
\hline (Harpagophytum sp.) & 2012 & 543.853 & 25.000 .000 & 46 \\
\hline Hoodia $^{\mathrm{a}}$ & 2008 & 3.595 & n.a & n.a \\
\hline (Hoodia gordonii) & 2012 & 1.900 & n.a & n.a \\
\hline Marulab & 2008 & 5.022 & 905.000 & 180 \\
\hline (Sclerocarya birrea) & 2012 & 6.080 & 1.003 .200 & 165 \\
\hline Ximenia $^{\mathrm{b}}$ & 2008 & 5.805 & 863.800 & 149 \\
\hline (Ximenia sp.) & 2012 & 3.810 & 560.561 & 147 \\
\hline Kalahari melon ${ }^{\mathrm{b}}$ & 2008 & 7.370 & 921.250 & 125 \\
\hline (Citrullus lanatus) & 2012 & 79 & 7.000 & 89 \\
\hline Namibian myrrh ${ }^{c}$ & 2008 & 6.094 & 304.270 & 50 \\
\hline (Commiphora wildii) & 2012 & 1.393 & 198.490 & 143 \\
\hline \multirow[t]{2}{*}{ Total } & 2008 & 714.886 & 23.994 .320 & 33.6 \\
\hline & 2012 & 508.797 & 26.795 .724 & 52.7 \\
\hline
\end{tabular}

n.a. not available

${ }^{\text {a }}$ Dried raw material

${ }^{\text {bSeed oil }}$

${ }^{\mathrm{C}}$ Resin + essential oil 
Nevertheless, further social, cultural, and political aspects need to be taken into account when analysing ABS/biotrade cases and respective arrangements between harvesters, producers, traders, and exporters.

\subsubsection{Devil's claw—From exploitative business to a trust-based trade relationship}

Devil's claw is widely distributed across South Africa, Botswana, Namibia, and Angola. Traditionally, the roots were used by the San and Nama communities to treat inflammatory ailments [65]. This knowledge was accessed in the early 1950s by a German colonial soldier, who send samples to a German pharmacy for analysis [66]. Later, the active chemical ingredient harpagoside was identified and efficacy for the treatment of rheumatic diseases was confirmed $[67,68]$. The resource is mainly wild-harvested under hard labour conditions in the Kalahari Desert. In the late 1990s, concern was raised on unsustainable harvest practices. The Devil's Claw Working Group (DCWG) was established to regulate the conditions of harvest and trade. In 2010, the National Policy on Utilization of Devil's Claw (Harpagophytum spp.) Products was adopted laying out detailed permit requirements [69]. A sustainable harvesting technique was developed and the Centre for Research Information Action in Africa-Southern Africa Development and Consulting (CRIAA-SADC) was commissioned to provide workshops and training for harvester groups [65]. While environmental conditions basically improved, social aspects remained largely unaffected. For example, a governmental stakeholder describes the persistent 'exploitative' business practice as follows:

"How do you make that industry less exploitative without compromising the entire business? How do you provide a bigger benefit to the traditional knowledge holders who have never been compensated? (...) The harvesters represent some of the poorest of the poor of communities in Namibia, who are so desperate for money that they will go sit in the middle of the Kalahari and dig roots and put them in bags and take them home and cut them up and dry them and sell them on to buyers at sometimes ludicrous low prices".

Recently, wild-harvesters in the Nyae Nyae and N\#a Jaqna conservancies were able to negotiate a supply contract directly with the exporter EcoSo Dynamics. In 2017, about 40 tonnes of raw material was purchased at a value of approximately 2 million N\$ [70]. However, when assuming an annual harvest between 500 and 700 tons it is estimated that more than $90 \%$ of devil's claw trade still remain unaffected by this agreement.

\subsubsection{Hoodia-From misappropriate use to a shareholder agreement}

Hoodia is a succulent, which grows in the Kalahari Desert in the Southern African region. The traditional knowledge mainly lies with the San people: beside general health applications, e.g. headache, stomach ache, asthma, and flu, the plant is well-known for its spiritual uses as well as a food and water substitute. In Namibia, further traditional uses have been reported for minority groups, e.g. Nama, Damara, and Topnaar, noting the use of Hoodia as a diabetes remedy [71] (p. 94). Despite these varied applications, in media publications Hoodia is predominantly described as a'hunger and thirst suppressant' used on long hunting trips [72].

The knowledge on Hoodia as an edible has already been documented in the early 1930 s as part of colonial botanical accounts. The information was re-accessed in the early 1960s by the South African research institution Council for Scientific and Industrial Research (CSIR), who initiated a project to inform the South African Defence Force (SADF) about nutritional properties of wild plants [71] (p. 95). Hoodia specimens were then analysed in the laboratory, however, it took until the mid-1990s to identify the active ingredient named P57. As a result, a patent was filed for the use of Hoodia as an appetite suppressant. In order to develop a botanical anti-obesity prescription drug, a license was issued to Phytopharm, a British-based phytomedical company, which was further granted to the pharmaceutical company Pfizer. When Pfizer terminated its nutraceutical R\&D program in 2003, the company Unilever invested in formulating a Hoodia-slimming drink as part of their SlimFast brand. An application for US-registration in 2007 was accompanied by investment into large-scale commercial cultivation [71].

These developments were urged by a public campaign, spearheaded by the NGO Biowatch South Africa stressing the missing acknowledgement and compensation of traditional knowledge holders. As a result, forced benefit-sharing negotiations were initiated and an agreement was reached between the Council for Scientific and Industrial Research and the South African San Council stating that if Hoodia products are commercialised, $6 \%$ royalty payments would become eligible for the knowledge holder [71]. However, under this agreement San communities would merely receive payments as 'compensation' for their knowledge, while still being mainly excluded from the business opportunity itself. In Namibia, the 'exclusive business development model' proposed by Unilever was challenged by a government initiative aiming to 
facilitate an integrated supply chain: the Hoodia Growers Association of Namibia (HOGRAN) was set-up not only to ensure that traditional knowledge holders would obtain equity shares in the commercial operation, but also to encourage them to become Hoodia-producer themselves. A stakeholder at the NBRI describes the model as follows:

"The supply chain would be a mixed supply chain. There would be some commercial farmers, who would be growing Hoodia under their own arrangements, and there would be community-based growers at homestead level. (...) And there were projects established to support, and train and establish infrastructure among the communities, working closely with the traditional authorities. There was no doubt around recognition of who were the original owners of the knowledge. It was well accepted within Namibia that it was the Nama and San. And part of that model would be that the traditional knowledge holders would be encouraged to become part of the business opportunity with shares in the commercial arm of the Hoodia Growers Association of Namibia and as suppliers of plant material, and not simply financially compensated for their knowledge".

Unfortunately, for many stakeholders out of a sudden, in 2008 Unilever abandoned their plan to develop Hoodia as a functional food by announcing safety and efficacy concerns. By emphasising potential hepatotoxic effects, which according to a current review presented by the National Institute of Diabetes and Digestive and Kidney Disease [73] are unlikely to occur, any business opportunity terminated for the whole South-African region.

\subsubsection{Namibian myrrh-From a resource inventory to a joint venture agreement}

The Namibian myrrh is a shrub, which occurrence is restricted to the Kunene Region, North West Namibia. Traditionally, the resin is used by the Himba people to perfume butterfat. In 2006, this knowledge was accessed as part of a resource inventory conducted by the Namibian NGO Integrated Rural Development and Nature Conservation (IRDNC). Prior informed consent was given by the community before further investigating the commercial potential. A "democratic resource management model" [74] (p. 21) was developed that is based on the establishment of communal resource rights, which a NGO-stakeholder describes as follows:

"We supported them to re-register themselves as a Community Forest, which gives them the legal right to those plant resources. The communities (...) are the legal owners of the resource, even though it is communal land. They are the legal entities. They can enter into contractual arrangements with a buyer".

In 2012 the Kunene Conservancies Indigenous Natural Products (KCINP) Trust was founded managing the communityowned Opuwo Processing Facility [75]. The produced essential oils are marketed under the brand Scents of Namibia. The main objectives of the KCINP Trust is "the upliftment and benefit sharing of the Kunene conservancies and community forests which market their natural resource products for the benefit of their members" (http://scentsofnamibia.com). Thereby, specific attention is given to integrate the principles of sustainability and social responsibility. Currently, the Trust is engaged in negotiations to establish joint venture agreements with potential buyers [74].

\subsection{Understandings of nature and respective practices with nature}

There are different actors involved in the Namibian bioeconomy: On the user side mainly industrial stakeholders are relevant, but non-commercial actors, e.g. research institutes, utilise biodiversity as well. Providers include state representatives as well as $\mathrm{CBO}$ s. Furthermore, intermediate actors, like NGOs, may be part of the negotiation as well. Understandings of 'nature' are often attributed in a stereotypical way: users favour simple and streamlined access requirements, while providers stress on the misappropriate acquisition of the resources. Here, a better differentiation is necessary paying attention towards the divers (and at times contradictory) conceptualisations of 'nature' across stakeholder groups (Table 2).

In Namibia, as already stated, biodiversity policies and laws are basically informed by the principle of sustainable development as laid down in the Namibian constitution. Thereby, biodiversity is not only relevant as a natural-material resource, e.g. for direct consumption, furthermore, its social aspects are stressed, e.g. when referred to as 'basic need', "basis of society", "welfare of the people", and 'foundation of the national economy'. For example, in the preface of the 2nd Namibian National Biodiversity Strategy and Action Plan it is stated: "Biodiversity is not only about plants and animals, but it is something fundamental to our survival and growth as a nation, that cuts across all sectors and levels in this country" [56]. Under the National Programme on Research, Science, Technology and Innovation the commercial use of IKS is facilitated as a 'nature-based solution': "Namibia is yet to fully embrace the potential of indigenous knowledge which is developed over centuries of learning from the environment" [61] (p. 14). The interrelation of natural and social aspects 


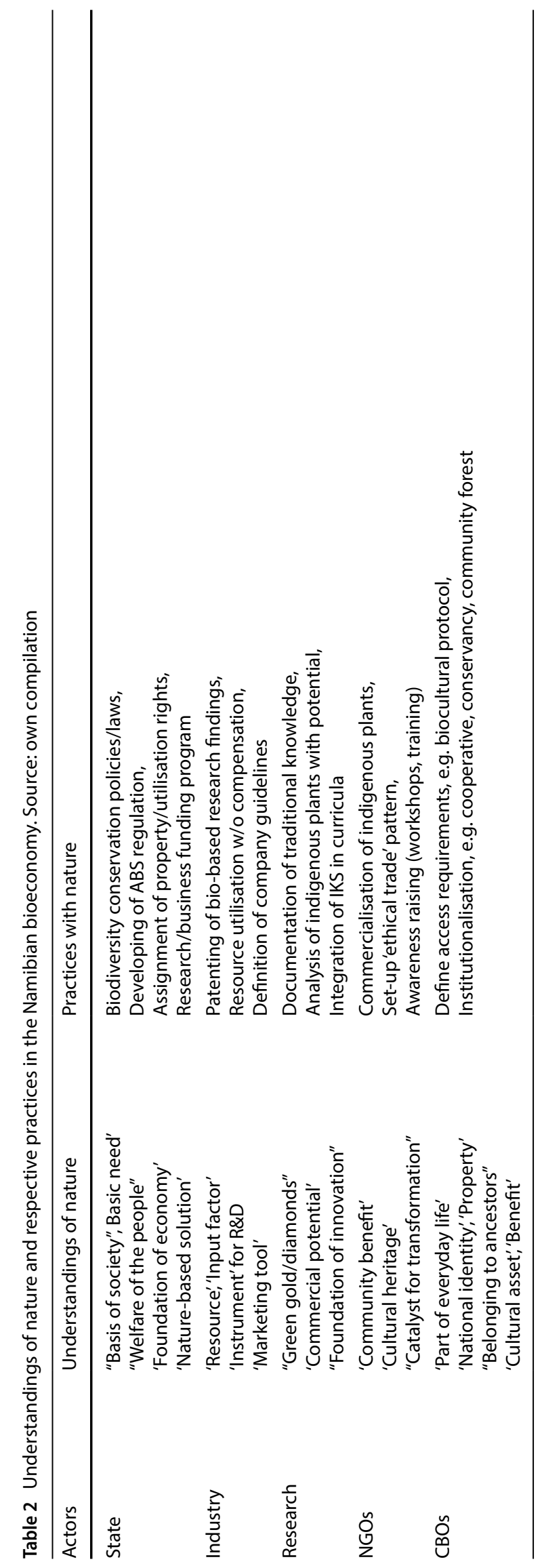


Fig. 3 The societal relations to nature in the Namibian bioeconomy (Source: own compilation)

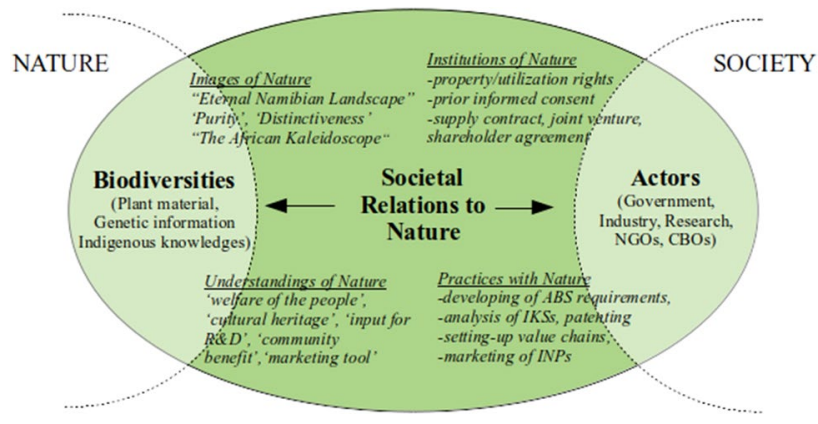

also becomes apparent when looking at ABS-related practices, e.g. the assignment of property/utilisation rights, the negotiation of bioprospecting/biotrade agreements and supporting bio-based research/businesses.

Companies utilise Namibian indigenous plants both as a 'resource' for production as well as an 'input factor' for R\&D, resulting into the assignment of intellectual property rights. Besides using traditional knowledge as an 'instrument' to target specific research leads, furthermore, it is employed as a'marketing tool' to further the companies' image of ethical trade. However, as long as no ABS regulation is in place, benefit-sharing initiatives mainly rely on industry's voluntary participation, e.g. by defining corporate standards, guidelines, and philosophies.

The University of Namibia (UNAM) facilitates a bio-based research agenda. Ethno-botanical studies are conducted to document the traditional uses of medicinal plants. Bioactive compounds from traditional plants are analysed in the laboratory for potential applications, thereby, along with the National Development Plan, mainly targeting on food and health related aspects [76-78]. Further, the integration of the IKS into the curriculum is promoted [79]. Besides an instrumental understanding of 'nature', e.g. describing IKS as the 'foundation of innovation' and 'economic potential' and biodiversity as 'green gold/diamonds', which need to be exploited, furthermore, a cultural-ethical understanding is prevailing as well. For example, Chimwamurombe et al. [80] (p. 9204/9207) describes the relation between communities and their natural resources as a 'coexistence', which need to be protected from biopiracy.

Several NGOs are involved in the commercialisation of Namibian INPs. For example, the NGO IRDNC promotes the establishment of community-based value chains to secure biodiversity as 'community benefit' [75]. The NGO CRIAA-SADC facilitates ethical trade to preserve traditions as 'cultural heritage' [81]. Under the UNEP Biotrade Project the Namibian bioeconomy is described as a 'catalyst for transitioning to a green economy' [22]. International NGOs are relevant as funding institutions to support national NGOs in conducting projects, publish reports and provide expertise to promote awareness around ABS-related issues.

Also several CBOs are engaged with ABS, thereby, employing a wide range of conceptualisations of 'nature.' For example, San and Nama people see indigenous plants as an 'integral part of everyday life'. Traditional knowledge serves as 'culture-defining practice' and facilitates a'national identity'. Furthermore, spiritual understandings of 'nature' are prevailing as well e.g. indigenous plants as 'belonging to the ancestors'. However, a rational-instrumental understanding of 'nature' is not absent: communities may promote bioprospecting activities to achieve 'additional income opportunities'. Namibian communities are engaged in defining ABS requirements. For example, currently the Khwee community in the Bwabwata National Park is developing a biocultural protocol [82].

Understandings of 'nature' and respective practices in the Namibian bioeconomy cannot be assigned to users and providers in a stereotypical way, instead, all actors, including governmental, industrial as well as civil-society stakeholders employ a rational-instrumental as well as normative-ethical understanding of 'nature'.

\subsection{Summary-The societal relations to nature in the Namibian bioeconomy}

When conceptualizing the SRN in the Namibian bioeconomy as an overlapping interface between the sphere of 'nature' and 'society', entailed inherent contradictions become apparent (see Fig. 3). Different actors are involved in the Namibian bioeconomy, including government, industry, and research as well as NGOs and CBOs. Biodiversities are relevant as plant materials, genetic information as well as indigenous knowledges.

The Namibian bioeconomy is predominantly characterised by images of 'nature' that explicitly or implicitly draw upon colonial notions, such as the 'eternal Namibian landscape'. When emphasizing the 'naturalness' of Namibian INPs, social issues tend to be neglected, thereby, reinforcing social-ecological inequalities. However, the image of the "Namibia-The African Kaleidoscope" potentially allows to integrate multi-fractured, culturally-diverse and constantly evolving SRN. 
With independence, in Namibia the commercialisation of INPs has been taken up as a polycentric approach based on multi-stakeholder involvement. The presented cases, namely Devil's claw, Hoodia and Namibian myrrh, show that institutions of 'nature' vary with regard to the provisions for ABS. Knowledges on the older resources were encountered as part of colonial explorations, whereby prior informed consent was given when accessing the newer resources. Benefitsharing arrangements (even when some never materialised and/or are only of small-scale) include supply contracts, shareholder and joint venture agreements.

Perspectives of actors involved cannot be assigned in a stereotypical way, instead, all stakeholders employ diverse understandings of 'nature': biodiversity and traditional knowledge are conceptualised as 'welfare of the people', 'cultural heritage, 'input for R\&D', 'community benefit', and 'marketing tool'. Despite the presence of both rational-instrumental and normative-ethical reasoning, commercial activities, such as validating the economic potential of indigenous plants, patenting of research findings, and setting-up value chains, are increasingly, but not necessarily linked to caring practices with 'nature', e.g. nature conservation and indigenous practices.

\section{Discussion}

In this paper, we analysed the SRN in the Namibian bioeconomy by drawing upon a social-ecological framework. When conceptualising SRN as 'mediating space' between 'nature' and 'society', they become apparent as every-day notions, both in terms of cultural-symbolic as well as natural-material aspects. Based on the research questions: Which SRN are prevailing? What inherent contradictions exist? Are certain perspectives favoured over others? in the analysis we focused on images, understandings, institutions and practices of/with 'nature'.

Starting out with the assumption that 'natural' and 'social' aspects are closely interrelated, we argued that inherent inequalities in the Namibian bioeconomy can only be overcome when looking at the contradictions within the SRN. As assumed, our analysis shows that in fact a number of inherent contradictions are characterising the Namibian bioeconomy. However, these do not merely become apparent as dichotomous structures, such as 'natural/social','traditional/ modern', and 'developed/industrialised, but also as trade-offs. Conflicting objectives arise especially around the questions: How to define the scope of ABS/biotrade? How to implement, monitor and enforce ABS provisions? Thereby, the rational-instrumental reasoning: How to create a market for biodiversity? tends to be favoured over the normative-ethical question: How to link commercial, environmental and social aspects?

Further, societal issues may be functionalised as 'natural idealisations' by drawing upon colonial notions. For example, the presentation of Hoodia as a 'hunger and thirst suppressant' is linked to the impression that desperate living conditions have mainly been unchanged since pre-colonial times. While the reflex-question: Whether desperate living conditions rather coincided with colonial encounters? may be misleading, as it implies that a "colonial narrative" could be validated within its historical context, more importantly, the "notion of desperately hungry and thirsty San running for days in the hot desert sand pursuing some animal" (as an interview stakeholder critically commented) does in fact delimit the San's agency today. This interpretation is supported by the statement made by a Pfizer-spokesperson that as the San people was nearly "extinct" no ABS-negotiation is of relevance anyway [71]. However, a 'socialisation' of natural aspects may occur as well. For example, the buyers request for a steady supply of plant material that could be fixed in advance, misses to account for the variability in production for a wild-harvested desert plant, like devil's claw, that cannot easily be overcome by a 'change of mentality'.

In conclusion, when conceptualising the entanglement between natural and social aspects as historic pattern of regulation, hierarchies and power relations are visualised. In Namibia, separating structures are constantly being challenged, e.g. by implementing an ABS regime, negotiating benefit-sharing agreements and defining biocultural protocols. However, simultaneously, when leaving the underlying conceptions of 'nature' unquestioned, divisions and associated inequalities are rather reinforced than overcome. Thus, strategies to capitalise the bioeconomy-despite their claim to facilitate inclusive and sustainable futures-may trigger "new dependencies", i.e. new mode of capitalist exploitation that is resting in colonial relations $[83,84]$.

Images of 'nature' that explicitly or implicitly draw upon colonial notions, such as the vast, untouched 'empty space', are frequently used to market Namibian INPs. When emphasising the 'naturalness' of INPs 'nature', by detaching indigenous plants from their social, cultural, and political context associated, culture may appear as static, pre-described, and thus, unchangeable. As a result, distinctive 'culturally-purified' natural products may not only appear as'naturally given', moreover, they may serve as functional idealisations, e.g. conceptualising biodiversity and traditional knowledge as an open 
access resource. Furthermore, the presentation of INPs as 'ancient naturals' based on 'secret wisdom' may spur concerns of local communities for the theft of their traditional knowledge.

However, when visualising the interrelation between natural and social aspects, it becomes apparent that there is no original, unaltered state of 'nature', but a constructed, manufactured one. Likewise, as Akuupa [85] has pointed out at the example of Namibian colonial and post-colonial cultural representation, it is critical to conceptualise culture not as static, but dynamic. According to Dutfield et al. [86] the label 'traditional' itself must be understood as a "colonial construct" that renders "cultures as static, fixed in time, and unable to adapt" (p. 1). Here, the word indigenous captures the dynamic nature of 'culture'.

In Namibia, the commercialisation of INPs has been taken up as a national approach: A 'Bioeconomy for All' is to be created based on the principle of benefit-sharing. Instead of adopting a pre-defined model, a bottom-up approach has been taken that is based on multi-stakeholder involvement. However, the question remains: If and in what regard the newly introduced ABS-law will impact historic pattern of regulation in the INPs industry? Especially in the situation of limited funds, the implementation, monitoring, and enforcement of ABS provisions may be limited. This has also been pointed out by Mosimane and Silva [57] (p. 108):"local governance institutions have limited capacity to develop benefitsharing schemes and that the national government fails to monitor and enforce policy requirements at community level".

In this regard, while at least theoretically, the implementation of an ABS regime has been promised as an 'efficiency generator' streamlining scattered approaches on the local, regional, national, and international level, Chinsembu and Chinsembu [87] described the Namibian ABS-architecture-in its current form -as "poisoned chalice": While the law is well intentioned to regulate commercial $A B S /$ biotrade, it may be overly restrictive to non-commercial bioprospecting, e.g. ethnobotanical studies conducted at universities (p. 27). While this is a fair point, however, from a social-ecological perspective, a strict division between commercial/non-commercial approaches may represents an obstacle by itself rather than a facilitator. In general, the ABS/biotrade interface is strongly interrelated as genetic material once 'explored' may become subject to commercialisation purposes at a later point [59] (p. 5). However, in practice, the regulation of ABS/biotrade will mainly be determined by the definition of basic terminology, e.g.'access,' 'genetic resources', 'traditional knowledge', and 'communities'. Muller et al. [88] highlight that the "shifting and changing scope of ABS" is a major challenge for its implementation: as long it is unclear of what is actually being regulated, there is no legal certainty (p. 1).

The analysis of Namibian ABS/biotrade cases shows that more sustainable bioeconomies tend to be realised when traditional knowledge holder form an integral part of the commercialisation scheme, e.g. as practised in the case of the Namibian Myrrh. In principle, pattern of exchange grounded in rather exploitative sourcing regimes, e.g. devil's claw, can be challenged both externally, e.g. by public campaign and the establishment of a permit regime, as well as internally, e.g. by providing trainings for harvesters and facilitating a closer interaction between actors. There are a wide range of different benefit-sharing mechanisms, including biotrade contracts, shareholder, and joint venture agreements. While small-scale INP-trade function as instrument for rural and local development [89], designed institutional changes may also exaggerate existing power asymmetries, and thus, be accompanied by unintended side-effects that run counter to ABS objectives e.g. as has been shown at the case of Marula [90].

Furthermore, our analysis shows that understandings of 'nature' must not be assigned in a stereotypical way between user and provider: all actors, including governmental, industrial, and civil society stakeholders employ divers (and at times contradictory) concepts, such as biodiversity as 'welfare of the people', 'input for R\&D', 'marketing tool', and 'cultural heritage.' However, in the face of existing power dynamics, a rational-instrumental understanding of 'nature' may be prioritised over a normative-ethical one. This has also been shown at the case of Hoodia negotiation, where the San people supported the negotiation of an ABS-agreement, despite the fact that the idea of 'selling' local knowledge is in opposition to their 'traditional way of life' [91].

Based on the empirical data we conclude that conceptualisations of 'nature' need to be taken into account when looking into the question: How to create and sustain an inclusive bioeconomy build upon the principle of 'fairness' and 'equity'? However, the question remains whether or not and in what ways these findings are relevant for the overall bioeconomy. Despite the fact that our results are mainly restricted to the Namibian bioeconomy, based on our findings, we question the simplified assumption that 'the bioeconomy', by definition, benefits business, society, and nature alike: (bio) technological applications do not act as a mere trigger for industrial modernisation, further social, cultural, and political innovations are relevant as well. Not only in Namibia, 'bioeconomies' present itself as a (new) multi-disciplinary research tool to study IKS, a (new) set of laws, regulations, and policies to promote ABS mechanism, as well as a variety of (new) INPs-businesses.

Even when increasingly a diversity-based approach is taken, acknowledging that there is not one single bioeconomy but many 'bioeconomies', the shaping of a (new) sustainable and well-being orientated bioeconomy may be biased 
towards a Western understanding. Thereby, alternative visions, e.g. ubuntu-based notions of sharing, are likely to be neglected. Especially concept that draw upon modernisation theory must be seen as highly critical as 'traditions' tend to be perceived as primitive, unevolved and inferior. However, under dependency theory, 'underdevelopment' tends to be externalised, while internal factors, e.g. bad governance, tend to be neglected [42, 43]. Thus, when asking: is Africa 'ready' for an integrated bioeconomy approach? Not only "multifaceted and interconnected management approaches to competitive biomass production and transformation" [92] (p. 33) are required, there is a need for a new economic paradigm that challenges the nature/culture-divide. Also when not explicitly noting, this idea has also been taken up by Oguntuase and Adu [93], who define the bioeconomy as a "new wave of economic system" that "combines, in a synergic way, both natural resources and technologies, with markets, people and policies to tackle societal challenges" (p. 2).

Further, we located the study of the Namibian bioeconomy within the broader sustainability debate. When conceptualising 'sustainable development' as a blueprint for discussion over desired societal developments that opens up a space to critically assess divergences within underlying objectives, strategies, practices and outcomes. For example, Eisenmenger [94] applied a social-ecological perspectives in the investigation of the effectiveness of the Sustainable Development Goals by focusing on the links between societal transformation and biophysical interactions of society with the natural environment and their iterative co-evolution: "A transformation towards sustainability has to go beyond proposals set with the SDGs; development has to merge an equal distribution of prosperity for all with ecological integrity, without depending predominantly on growth-oriented measurements of progress (p. 9).

Drawing on a feminist perspective, according to Mölders [95] the sustainability-debate can be structured along the line productivity/re-productivity: while an understanding of 'nature' as an object to be utilised is connected to the productive sphere, an understanding of 'nature' as a subject to be protected is connected to the reproductive sphere. When prioritising productive assets, e.g. commercial uses, unproductive ones, e.g. subsistence uses, are minorised. The demarcation between productive/reproductive lies at the heart of the Sustainable Development Goals. Despite the claim that action must go hand-in-hand, economically-informed goals, e.g. Decent Work and Economic Growth and Industry, Innovation and Infrastructure may be favoured over social ones, e.g. Good Health and Well-Being and Quality Education. In the attempt to address the implications of an "unsustainable world" [96], there is a need to facilitate a "critical emancipatory understanding of sustainability" [97] (p. 99). The concept of (re)productivity allows combining questions of social and natural production and preproduction as dialectic relation that mutual depend upon each other. This allows developing a new economic rationale that is not solely based on the 'commodification of nature', but also concerned with the "socialecological conditions that are not monetised and capitalistically oriented" [ibid].

Considering this argument, we must admit that in our analysis by focusing on the commercial utilisation of indigenous plants and knowledges we may have fallen behind our own aspirations: Future research should consider innovative aspects for subsistence use as well, e.g. marama bean (Tylosema esculentum) and indigenous leafy vegetable, such as ombidi (Cleome gynandra), ekwakwa (Amaranthus thunbergii) and omutete (Hibiscus sabdariffa).

Last, but not least: What are the implications for research, practice and/or society? In general, the social-ecological conceptual framework provides a useful tool to visualise dividing structures that act as unexpressed undercurrents that potentially prohibit sustainable development. As Béné et al. [98] highlight: different views and interpretations exist about the nature of the 'crisis', and consequently, about how to 'fix' the problem. As a mediating approach, social-ecological research allows to study the complex challenges at the interface of nature and society, by outlining transdisciplinary research as a step-by-step process that helps to define an epistemic object based on a shared problem perception [99]. Furthermore, a social-ecological perspective may also be relevant whenever a theory becomes translated into a practical context, e.g. development project-management and environmental policy-making.

Future research should look into the dialectics entailed in the conceptualisation of 'sustainability visions', or with the words of Liverman [23] there is a need for alternative development visions that take into account "local, subaltern and indigenous voices and agency, reassert the significance of social protections, and admit the inevitable trade-offs and contradictions between growth and environment (p. 181).

\section{Conclusions}

In this paper, we analysed the inherent contradictions within the SRN in the Namibian bioeconomy. By taking a socialecological perspective, specific attention was drawn on historic pattern and structures regulating the commercial utilisation of indigenous plants and knowledges. We conclude that when applying colonial images of 'nature' that reinforce the segregation between the 'natural' and the 'social', the 'transformative potential' of the bioeconomy is limited. We found 
that the effectiveness of $A B S$ is constrained when prioritising a rational-instrumental reasoning over a normative-ethical one, e.g. when disqualifying subsistence uses over commercial ones. Nevertheless, the Namibian case study shows that by taking a bottom-up stakeholder-involved approach allows for the creation of functional benefit-sharing systems. However, it is critical not to assign understandings of 'nature' in a stereotypical way between user and provider, but to draw attention to the dialectics entailed in the conception, making, and management of 'nature'. Future bioeconomy research should investigate the dichotomous structures and trade-offs between biodiversity commercialisation, conservation and poverty alleviation. The social-ecological framework provides a useful tool for a critical assessment of underlying conceptions of 'nature' and respective functional idealisations. As a transdisciplinary approach it allows to build a shared boundary concept of 'sustainability'. A more diversified awareness towards the entanglement between cultural-symbolic and material-biophysical aspects is relevant at any theory-practice interface, including development project-management and environmental policy-making.

Acknowledgements We thank the National Botanical Research Institute (NBRI) and the Integrated Rural Development and Nature Conservation (IRDNC) for vivid discussions on sustainability aspects in the Namibian bioeconomy field. Further, we thank Dr. Tristan Hauser for his feedback on an early draft and Prof. Tanja Mölders for her comments on the sustainability aspect in the final draft. Further, we thank two anonymous reviewers for their input.

Authors' contributions The conceptualisation, investigation, and original draft preparation was carried out by AH-H. PMC and AC reviewed and edited the paper. All authors read and approved the final manuscript.

Funding Open Access funding enabled and organized by Projekt DEAL.

Data/Code availability Not applicable.

Competing interests The authors declare no conflict of interest.

Open Access This article is licensed under a Creative Commons Attribution 4.0 International License, which permits use, sharing, adaptation, distribution and reproduction in any medium or format, as long as you give appropriate credit to the original author(s) and the source, provide a link to the Creative Commons licence, and indicate if changes were made. The images or other third party material in this article are included in the article's Creative Commons licence, unless indicated otherwise in a credit line to the material. If material is not included in the article's Creative Commons licence and your intended use is not permitted by statutory regulation or exceeds the permitted use, you will need to obtain permission directly from the copyright holder. To view a copy of this licence, visit http://creativecommons.org/licenses/by/4.0/.

\section{References}

1. Kirchner M. The emerging bioeconomy: industrial drivers, global impact, and international strategies. Ind Biotechnol. 2014. https://doi. org/10.1089/ind.2014.1500.

2. Adamowicz M. Bioeconomy: concept, application and perspective. Probl Agric Econ. 2017;1(350):29-49.

3. Kahle LR, Gurel-Atay E. Introduction to the psychology of communicating sustainability. In: Kahle LR, Gurel-Atay E, editors. Communicating sustainability for the green economy. New York: M.E. Sharpe; 2014. p. 3-21.

4. Virgin I, Morris EJ. Creating sustainable bioeconomies. The bioscience revolution in Europe and Africa. New York: Routledge; 2017.

5. Anonymous. A bio-based, reuse economy can feed the world and save the planet. In: UN News. 2018. https://www.un.org/sustainabl edevelpment/bloog/2018/04/a-bio-based-reuse-economy-can-feed-the-world-and-save-the-planet-un-agency/. Accessed 11 Nov 2018.

6. Kristinsson HG, Jörundsdóttir HÓ. Food in the bioeconomy. Trends Food Sci Technol. 2019. https://doi.org/10.1016/j.tifs.2018.10.011.

7. El-Chichakli B, von Braun J, Lang C, Barben D, Philip J. Policy: five cornerstones of a global bioeconomy. Nature. 2016;535:221-3.

8. Lokko Y, Hejde M, Schebesta K, Scholtès P, van Montagu M, Giacca M. Biotechnology and the bioeconomy: towards inclusive and sustainable industrial development. N Biotechnol. 2018. https://doi.org/10.1016/j.nbt.2017.06.005.

9. McCormic K, Kautto N. The bioeconomy in Europe: an overview. Sustainability. 2013. https://doi.org/10.3390/su5062589.

10. Richardson B. From a fossil-fuel to a biobased economy: the politics of industrial biotechnology. Environ Plann C. 2012. https://doi. org/10.1068/c10209.

11. Székács A. Environmental and ecological aspects in the overall assessment of bioeconomy. J Agric Environ Ethics. 2017. https://doi. org/10.1007/s10806-017-9651-1.

12. Bugge MM, Hansen T, Klitkou A. What is the bioeconomy? A review of the literature. Sustainability. 2016. https://doi.org/10.3390/su807 0691.

13. D'Amato D, Droste N, Allen B, Kettunen M, Lähtinen K, Korhonen J, Leskinen P, Matthies BD, Toppinen A. Green, circular, bioeconomy: a comparative analysis of sustainability avenues. J Clean Prod. 2017. https://doi.org/10.1016/j.jclepro.2017.09.053.

14. German Bioeconomy Council. Communiqué global bioeconomy summit 2015. Making bioeconomy work for sustainable development. 2015. https://gbs2015.com/fileadmin/gbs2015/Downloads/Communique_final.pdf. Accessed 17 Nov 2018. 
15. German Bioeconomy Council. Communiqué global bioeconomy summit 2018. Innovation in the global bioeconomy for sustainable and inclusive transformation and Wellbeing. 2018. https://biooekonomierat.de/fileadmin/Publikationen/empfehlungen/GBS_2018_Commu nique.pdf. Accessed 17 Nov 2018.

16. von Braun J. Foreword. In: Virgin I, Morris EJ, editors. Creating sustainable bioeconomies. The bioscience revolution in Europe and Africa. New York: Routledge; 2017. p. XV-XVI.

17. Hoy AQ. Africa cultivates innovation to boost global research. Science. 2018. https://doi.org/10.1126/science.360.6387.391.

18. Deutsche Gesellschaft für Internationale Zusammenarbeit (GIZ). Industry brief: bioinnovation Africa: 2019. https://www.giz.de/en/downl oads/giz2019-en-bioinnovation-africa.pdf. Accessed 22 May 2019.

19. Gottwald FT, Krätzer A. Irrweg Bioökonomie. Berlin: Suhrkamp Verlag; 2014.

20. Kropp C. "Natur": Soziologische Konzepte. Politische Konsequenzen. Wiesbaden: Springer Fachmedien; 2002.

21. Reid WW, Laird SA, Gámez R, Sittenfeld A, Janzen DH, Gollin MA, Juma C. A new lease on life. In: Reid WW, Laird SA, Gámez R, Sittenfeld A, Janzen DH, Gollin MA, Juma C, editors. Biodiversity prospecting using genetic resources for sustainable development. Washington: World Resource Institute; 1993. p. 1-52.

22. United Nations Environment Programme (UNEP). Green economy sectoral study: biotrade: a catalyst for transitioning to a green economy in Namibia. 2012. http://hdl.handle.net/20.500.11822/25957. Accessed 17 Nov 2018.

23. Liverman DM. Geographic perspectives on development goals: constructive engagements and critical perspectives on the MDGs and the SDGs. Dialogues Hum Geogr. 2018;8(2):168-85. https://doi.org/10.1177/2043820618780787.

24. Becker E, Jahn T. Soziale Ökologie: Grundzüge einer Wissenschaft von den gesellschaftlichen Naturverhältnissen. Frankfurt A. M: Campus; 2006.

25. Brand KW, Kropp C. Naturverständnisse in der Soziologie. In: Rink D, Wächter M, editors. Naturverständnisse in der Nachhaltigkeitsforschung. Frankfurt: Camous Verlag; 2004.

26. Becker E, Hummel D, Jahn T. Gesellschaftliche Naturverhältnisse als Rahmenkonzept. In: Groß M, editor. Handbuch Umweltsoziologie. Wiesbaden: VS Verlag für Sozialwissenschaften; 2011. p. 75-96.

27. Hummel D, Jahn T, Keil F, Liehr S, Stieß I. Social ecology as critical, transdisciplinary science: conceptualizing, analyzing and shaping societal relations to nature. Sustainability. 2017. https://doi.org/10.3390/su9071050.

28. Görg C. Gesellschaftliche Naturverhältnisse. Münster: Westfälisches Dampfboot; 1999.

29. Görg C, Brand U, Haberl H, Hummel D, Jahn T, Liehr S. Challenges for social-ecological transformations: contributions from social and political ecology. Sustainability. 2017. https://doi.org/10.3390/su9071045.

30. Bowen GA. Document analysis as a qualitative research method. Qual Res. 2009. https://doi.org/10.3316/QRJ0902027.

31. Rosenthal G, Loch U. Das narrative Interview. In: Schaeffer D, Müller-Mundt G, editors. Qualitative Gesundheits- und Pflegeforschung. Bern: Huber; 2002. p. 221-32.

32. Kruse J. Qualitative Interviewforschung. Ein integrativer Ansatz. Weinhein: Beltz Juventa; 2014.

33. Wallace MA. History of Namibia: from the beginning to 1990. Oxford: University Press; 2011.

34. Katjavivi PH. A history of resistance in Namibia. Oxford: James Currey Ltd; 1988.

35. Dale R. The Namibian war of independence, 1966-1989: diplomatic, economic and military campaigns. Jefferson: McFarland \& Company; 2014.

36. Kinahan J. From the beginning: the archaeological evidence. In: Wallace M, editor. A history of Namibia: from the beginning to 1990. Oxford: University Press; 2011. p. 15-44.

37. Friedman JT. Imagining the post-apardheid state. An ethnographic account of Namibia. New York: Berghahn Books; 2013.

38. Bollig M, Gewald JB. People, cattle and land: transformations of a pastoral society in South Western Africa. Köln: R. Köppe Verlag; 2000.

39. Akuupa MU, Kornes G. From 'one Namibia, one nation' towards 'unity in diversity'? Shifting representations of culture and nationhood in Namibian independence day celebrations, 1990-2010. Anthropol S Afr. 2013. https://doi.org/10.1080/23323256.2013.11500041.

40. Chinsembu KC, Hedimbi M, Mukaru WC. Putative medicinal properties of plants from the Kavango region, Namibia. J Med Plant Res. 2011. https://doi.org/10.5897/JMPR11.1135.

41. Nnaemeka AN. Towards an alternative development paradigm for Africa. Soc Sci J. 2009. https://doi.org/10.1080/09718923.2009.11892 749.

42. Dibua Jl. Modernization and the crisis of development in Africa: the Nigerian experience. Burlington: Ashgate Publishing Ltd; 2006.

43. Matunhu JA. Critique of modernization and dependency theories in Africa: critical assessment. Afr J Hist Cult. 2011;3(5):65-72.

44. Worldbank. Country profile: Namibia. https://databank.worldbank.org/data/views/reports. Accessed 17 Nov 2018.

45. David B, Wolfender JL, Dias DA. The pharmaceutical industry and natural products: historical status and new trends. Phytochem Rev. 2015. https://doi.org/10.1007/s11101-014-9367-z.

46. Hamilton AC. Medicinal plants, conservation and livelihood. Biodivers Conserv. 2004. https://doi.org/10.1023/B:BIOC.0000021333.23413 .42 .

47. ten Kate K, Laird SA. The commercial use of biodiversity: access to genetic resources and benefit-sharing. London: Earthscan; 1999.

48. Richerzhagen C. Effectiveness and perspectives of access and benefit-sharing regimes in the Convention on Biological Diversity: a comparative analysis of Costa Rica, the Philippines, Ethiopia and the European Union. Ph.D., Rheinische Friedrich-Wilhelms-Universität Bonn. 2007. https://hss.ulb.uni-bonn.de/2007/1211/1211.pdf. Accessed 27 Nov 2018.

49. Sukhdev P, Wittmer H, Miller D. The economics of ecosystems and biodiversity: challenges and responses. In: Helm D, Hepburn C, editors. Nature in the balance: the economics of biodiversity. Oxford: University Press; 2014. p. 135-52.

50. Siebenhüner B, Dedeurwardere T, Brousseau E. Introduction and overview to the special issue on biodiversity conservation, access and benefit-sharing and traditional knowledge. Ecol Econ. 2005. https://doi.org/10.1016/j.ecolecon.2004.12.012.

51. Crouch NR, Douwes E, Wolfson MM, Smith GF, Edwards T. South Africa's bioprospecting, access and benefit-sharing legislation: current realities, future complications, and a proposed alternative. S Afr J Sci. 2008;104:355-66. 
52. Shikongo S. An empirical investigation into the factors critical to the effectiveness of ABS implementation at the national and international levels. Ph.D., Rheinische Friedrich-Wilhelms-Universität Bonn. 2015. https://bonndoc.ulb.uni-bonn.de/xmlui/handle/20.500.11811/6248 Accessed 28 Nov 2018.

53. Sanzila G. Namibian Constitution celebrated, 11 th February 2020. Parliamentary News. https://parliament.na/index.php/parliamentarynews/156-latest-news-2020. Accesses 8 Sept 2020.

54. Republic of Namibia. The Constitution of the Republic of Namibia. Windhoek. 1990. https://gov.na/constitution. Accessed 28 Nov 2018.

55. Ministry of Environment and Tourism (MET). Namibia's 1st national biodiversity strategy and action plan. 1994-2005. Windhoek. 1994. http://www.met.gov.na. Accessed 17 Nov 2018.

56. Ministry of Environment and Tourism (MET). Namibia's 2nd national biodiversity strategy and action plan. 2013-2022. Windhoek. 2014. http://www.met.gov.na. Accessed 17 Nov 2018.

57. Mosimane AW, Silva JA. Local governance institutions, CBNRM, and benefit-sharing systems in Namibian conservancies. J Sustain Dev. 2015. https://doi.org/10.5539/jsd.v8n2p99.

58. Nkhata BA, Breen C, Mosimane A. Engaging common property theory: implications for benefit sharing research in developing countries. Int J Commons. 2012. https://doi.org/10.18352/ijc.330.

59. Suleman KK. The interface between access and benefit-sharing and biotrade in Namibia: exploring the potential areas of synergy. Occasional Paper. South African Institute of International Affairs (SAIIA). 2017. https://saiia.org.za/research/the-interface-between-access-andbenefit-sharing-and-biotrade-in-namibia-exploring-potential-areas-of-synergy/. Accessed 17 Nov 2018.

60. Jauhiainen JS, Hooli L. Indigenous knowledge and developing countries' innovation systems: the case of Namibia. Int J Innov Stud. 2017. https://doi.org/10.3724/SP.J.1440.101007.

61. National Commission on Research, Science and Technology (NCRST). The national programme on research, science, technology and innovation 2014/15 to 2016/17. http://www.ncrst.na. Accessed 17 Nov 2018.

62. Republic of Namibia. Access to biological and genetic resources and associated traditional knowledge act, Windhoek. 2017. www.parli ament.na. Accessed 17 Nov 2018.

63. Millennium Challenge Account (MCA). Indigenous natural products in Namibia. In: INP Market Bulletin, Volume 1. 2010 http://www.nbri. org.na/sections/economic-botany/inp. Accessed 17 Nov 2018.

64. Millennium Challenge Account (MCA). Indigenous natural products in Namibia. In: INP Market Bulletin, Volume 6. 2013. http://www.nbri. org.na/sections/economic-botany/inp. Accessed 17 Nov 2018.

65. Cole D. Devil's claw. (H. procumbens \& H. zeyheri). In Indigenous plant products in Namibia. Windhoek: Venture Publications; 2014. http:// www.nbri.org.na/sections/economic-botany/inp. Accessed 28 Nov 2018.

66. Wegener T. Zur klinischen Wirksamkeit der südafrikanischen Teufelskralle (Harpagophyti radix) bei Patienten mit Cox. und Gonarthrose. Ph.D., University of Osnabrück. 2005. https://repositorium.ub.uniosnabrueck.de/bitstream/urn:nbn:de:gbv:700-2006052225/2/E-Diss5 64_thesis.pdf. Accessed 28 Nov 2018.

67. Eichler O, Koch C. Über die antiphlogistische, analgetische und spasmolytische Wirksamkeit von Harpagosid, einem Glykosid aus der Wurzel von Harpagophytum procumbens DC. Arzneimittelforschung. 1970;20(1):107-9.

68. Georgiev MI, Ivanovska N, Alipieva K, Dimitrova P, Verpoorte R. Harpagoside: from Kalahari desert to pharmacy shelf. Phytochemistry. 2013. https://doi.org/10.1016/j.phytochem.2013.04.009.

69. Ndeinoma A, Wiersum KF, Arts B. The governance of indigenous natural products in Namibia: a policy network analysis. Environ Manage. 2018. https://doi.org/10.1007/s00267-017-0968-3.

70. Anonymous. Harvesting, curing and selling dried devil's claw earned Bushmen communities nearly N\$2 million in 2018 . In: Namibia economist. 2018. https://economist.com.na/40313/environment/harvestingcuring-and-selling-dried-devils-claw-earned-bushmencommunities-nearly-n2-million-in-2018/. Accessed 15 Dec 2018.

71. Wynberg R, Chennells R. Green diamonds of the South: an overview of the San-hoodia case. In: Wynberg R, editor. Indigenous peoples, consent and benefit sharing: lessons from the San-hoodia case. London: Springer; 2009. p. 89-126.

72. Vermaak I, Hamman JH, Viljoen AM. Hoodia gordonii: an up-to-date review of a commercially important anti-obesity plant. Planta Med. 2011. https://doi.org/10.1055/s-0030-1250643.

73. Anonymous. LiverTox: Clinical and Research Information on Drug-Induced Liver Injury. National Institute of Diabetes and Digestive and Kidney Diseases. 2012. https://www.ncbi.nIm.nih.gov/books/NBK548704/. Accessed 26 Sept 2020.

74. Integrated Rural Development and Nature Conservation (IRDNC). Strategic plan 2015-2025. http://www.irdnc.org.na/pdf/IRDNC-Strat egic-Plan.pdf. Accessed 17 Nov 2018.

75. Nott K. Commiphora (C. wildii). In: MCA. Indigenous plant products in Namibia. Windhoek: Venture Publications. 2014. http://www.nbri. org.na/sections/economic-botany/inp/ Accessed 28 Nov 2018.

76. Cheikhyoussef A, Shapi M, Matengu K, Mu AH. Ethnobotanical study of indigenous knowledge on medicinal plant use by traditional healers in Oshikoto region, Namibia. J Ethnobiol Ethnomed. 2011. https://doi.org/10.1186/1746-4269-7-10.

77. Cheikhyoussef A, Embashu W. Ethnobotanical knowledge on indigenous fruits in Ohangwena and Oshikoto regions in Northern Namibia. J Ethnobiol Ethnomed. 2013. https://doi.org/10.1186/1746-4269-9-34.

78. Chinsembu KC. Bioprospecting for 'green diamonds': medicinal plants used in the management of HIV/AIDS-related conditions. In: Chinsembu KC, Cheikhyoussef A, Mumbengegwi D, Kandawa-Schulz M, Kasanda CD, Kazembe L, editors. Indigenous knowledge of Namibia. Windhoek: University of Namibia Press; 2015. p. 9-40.

79. Mukumbu Chinsembu GM, Hamunyela M. To integrate or not: exploring the prospects and challenges of integrating indigenous knowledge at the University of Namibia. In: Chinsembu KC, Cheikhyoussef A, Mumbengegwi D, Kandawa-Schulz M, Kasanda CD, Kazembe L, editors. Indigenous knowledge of Namibia. Windhoek: University of Namibia Press; 2015. p. 361-77.

80. Chimwamurombe P, Mapaure I, Claassen P. Understanding the relationship between indigenous (traditional) knowledge systems (IKS), and access to genetic resources and benefits sharing (ABS). Afr J Biotechnol. 2010. https://doi.org/10.5897/AJB2010.000-3346.

81. Mallet M, den Adel-Sheehama S. Marula. (Sclerocarya birrea). In Indigenous plant products in Namibia. Windhoek: Venture Publications; 2014. http://www.nbri.org.na/sections/economic-botany/inp. Accessed 28 Nov 2018. 
82. ABS-Initiative. Sharing experiences and key lessons on bio-cultural community protocol development and utilization. In: African Biocultural community protocol initiative workshop, Nairobi, Nov 2014. http://www.abs-initiative.info/countries-and-regions/africa/kenya /sharing-experiences-and-key-lessons-on-bio-cultural-community-protocols/. Accessed 14 Nov 2018.

83. Amadi L. Africa: Beyond the "new" dependency: a political economy. Afr J Pol Sci Int Relat. 2012. https://doi.org/10.5897/AJPSIR12.022.

84. Death C. The green economy in South Africa: global discourses and local politics. Politikon. 2014. https://doi.org/10.1080/02589 346.2014.885668.

85. Akuupa M. National culture in post-apartheid Namibia: state-sponsored cultural festivals and their histories. Basel: Basler Afrika Bibliographien; 2011.

86. Dutfield G, Wynberg R, Laird S, Ives S. Policy brief: benefit sharing and traditional knowledge: unsolved dilemmas for implementation. The challenge of attribution and origin: Traditional knowledge and access and benefit sharing. Voices for BioJustice. 2020. https://www. voices4biojustice.org/wp-content/uploads/2017/12/Traditional-Knowledge-Policy-Brief-1.pdf. Accessed 26 Oct 2020.

87. Chinsembu WW, Chinsembu KC.'Poisoned chalice': law on access to biological and genetic resources and associated traditional knowledge in Namibia. Resources. 2020. https://doi.org/10.3390/resources9070083.

88. Muller M, Laird S, Wynberg R. Policy brief: why defining the scope of access and benefit sharing matter. Voices for BioJustice. 2020. https ://www.voices4biojustice.org/wp-content/uploads/2017/12/ABS-Scope-Policy-Brief-1.pdf. Accessed 26 Oct 2020.

89. Henry G, Trigo EJ. The knowledge based bio-economy at work: from large scale experiences to instruments for rural and local development. Montpellier: ISDA. 2010. https://agritrop.cirad.fr/557872/1/document_557872.pdf. Accessed 08 Sept 2020.

90. Watanabe S. An institutional analysis of biotrade contract implementation: the case of Namibian Marula Plant Oil. Herzogenrath: Shaker Verlag; 2015.

91. Vermeylen S. From life force to slimming aid: exploring views on the commodification of traditional medicinal knowledge. Appl Geogr. 2008. https://doi.org/10.1016/j.apgeog.2008.02.003.

92. Abass A. Is Africa "ready" for an integrated bioeconomy approach? Opinian Rural 21. 2014. https://www.rural21.com/english/news/detai I/article/is-africa-ready-for-an-integrated-bioeconomy-approach.html. Accessed 08 Sept 2020.

93. Oguntuase OJ, Adu OB. Bioeconomy as climate action: how ready are African Countries? In: Leal Filho W, Ogugu N, Ayal D, Adelake L, da Silva I, editors. African handbook of climate change adaptation. Cham: Springer; 2020. https://doi.org/10.1007/978-3-030-42091-8_82-1.

94. Eisenmenger N, Pichler M, Krenmayr N, Noll D, Plank B, Schalmann E, Wandl MT, Gingrich S. The Sustainable Development Goals prioritize economic growth over sustainable resource use: a critical reflection on the SDGs from a socio-ecological perspective. Sustain Sci. 2020. https://doi.org/10.1007/s11625-020-00813-x.

95. Mölders T. Gesellschaftliche Naturverhältnisse zwischen Krise und Vision. Eine Fallstudie im Biosphärenrervat Mittelelbe. München: Oekom; 2010.

96. Filho WL, Wolf F, Salvia AL, Beynaghi A, Shulla K, Kovaleva M, Vasconcelos RP. Heading towards an unsustainable world: some of the implications of not achieving the SDGs. Discov Sustain. 2020. https://doi.org/10.1007/s43621-020-00002-x.

97. Mölders T. Rethinking gender: feminist perspectives on Sustainable Development Goals in the light of (re)productivity. GAIA. 2019;28(2):95-9.

98. Béné C, Oosterveer P, Lamotte L, Brouwer ID, de Haan S, Prager SD, Talsma EF, Khoury CK. When food systems meet sustainability-current narratives and implications for actions. World Dev. 2019. https://doi.org/10.1016/j.worlddev.2018.08.011.

99. Liehr S, Röhrig J, Mehring M, Kluge T. How the social-ecological systems concept can guide transdisciplinary research and implementation: addressing water challenges in Central Northern Namibia. Sustainability. 2017. https://doi.org/10.3390/su9071109.

Publisher's Note Springer Nature remains neutral with regard to jurisdictional claims in published maps and institutional affiliations. 